\title{
Instrumentos de Avaliação Psicológica em Orientação de Carreira: Análise da Produção Nacional
}

\author{
Leonardo de Oliveira Barros ${ }^{1}$ \\ ${ }^{1}$ Universidade Federal da Bahia, BA, Brasil.
}

\author{
Rodolfo Augusto Matteo Ambiel ${ }^{2}$ \\ ${ }^{2}$ Universidade São Francisco, SP, Brasil.
}

\begin{abstract}
Resumo: Este estudo teve como objetivo realizar uma revisão integrativa da produção científica nacional acerca do uso de instrumentos de avaliação psicológica no contexto de orientação profissional e de carreira no período de 2000 a 2017. A busca ocorreu no mês de junho de 2018 , utilizando descritores correspondentes a "avaliação psicológica" e "orientação profissional" nas bases PePSIC, INDEXPSI, BVS-Psi, BVS-Saúde e no Google Acadêmico. Após a triagem de 1.376 artigos, elegeram-se 79 que atendiam aos critérios de inclusão, como ser estudo empírico com amostra brasileira e ter sido publicado em revistas nacionais. Os resultados indicaram crescimento do número de publicações a partir de 2003, com surgimento de pesquisadores além do eixo Sul-Sudeste. Foram contabilizados 69 instrumentos nas pesquisas e percebeu-se o início de investigações pautando temas e públicos não ligados apenas à escolha profissional, mostrando uma tendência de expansão da área para além do contexto escolar. Os instrumentos mais utilizados nas pesquisas foram a Escala de Aconselhamento Profissional, o Questionário de Busca Autodirigida e o Teste de Foto de Profissões, reforçando a forte tendência da avaliação de interesses profissionais na área.
\end{abstract}

Palavras-chave: Orientação Vocacional, Testes Psicológicos. Medidas.

\section{Psychological Assessment Instruments in Vocational Guidance: Analysis of National Production}

\begin{abstract}
This study is an integrative review of the national scientific production about the use of psychological assessment instruments in the context of Vocational and Career Guidance from 2000 to 2017. The search occurred in June 2018 using descriptors corresponding to "psychological assessment" and "vocational guidance" in the databases PePSIC, Index-Psi, BVS-Psi and BVSSaúde and Google Scholar. After screening of 1,376 articles, 79 were chosen for meeting the inclusion criteria, such as being an empirical study with a Brazilian sample and published in Brazilian journals. The results indicated a growth in the number of publications starting from 2003 with the emergence of researchers, in addition to a South-Southeast concentration. In addition, 69 instruments were counted in the surveys and the beginning of investigations was observed, focusing on themes and audiences that were not exclusively related to the professional choice, showing a trend where the field expanded beyond the school context. The most used instruments were Escala de Aconselhamento Profissional, Questionário de Busca-Autodirigida and Teste de Foto das Profissões, reinforcing the strong tendency to evaluate professional interest in the field.
\end{abstract}

Keywords: Vocational Guidance, Psychological Tests, Measurement. 


\title{
Instrumentos de Evaluación Psicológica en Orientación de Carrera: Análisis de la producción nacional
}

\begin{abstract}
Resumen: Este estudio tuvo como objetivo realizar una revisión integrativa de la producción científica nacional acerca del uso de instrumentos de evaluación psicológica en el contexto de orientación profesional y de carrera en el período de 2000 a 2017. La búsqueda ocurrió en el mes de junio de 2018 utilizando descriptores correspondientes a "evaluación psicológica" y "orientación profesional" en las bases PePSIC, INDEX-PSI, BVS-Psi y BVS-Salud y Google Académico. Tras la clasificación de 1.376 artículos, fueron elegidos 79 que atendían a los criterios de inclusión, tales como ser estudio empírico con muestra brasileña y haber sido publicado en revistas nacionales. Los resultados indicaron crecimiento del número de publicaciones a partir del año 2003 con surgimiento de investigadores además del eje Sur-Sureste. Además, se contabilizaron 69 instrumentos en las investigaciones y se percibió el inicio de investigaciones pautando temas y públicos no vinculados solo a la elección profesional, mostrando una tendencia de expansión del área más allá del contexto escolar. Los instrumentos más utilizados en la investigación fueron: Escala de Aconselhamento Profissional, Questionário de BuscaAutodirigida y Teste de Foto das Profissões, lo que refuerza la fuerte tendencia de la evaluación de intereses profesionales en el área.
\end{abstract}

Palabras clave: Orientación Vocacional. Pruebas Psicológicas. Medidas.

\section{Introdução}

As atuações em Orientação Profissional e de Carreira tiveram início em 1907 nos Estados Unidos com os trabalhos de Frank Parsons, que acreditava na importância de preparar os jovens para o processo de transição escola-trabalho, pois isso poderia gerar mudanças sociais significativas na adaptação ao campo laboral (Ribeiro \& Uvaldo, 2007). No Brasil, as práticas de Orientação Profissional e de Carreira tiveram início em 1920, porém o crescimento da área ocorreu a partir de 1940 com os estudos da influência da Psicologia sobre a Organização Racional do Trabalho, com o objetivo básico de auxiliar no ajuste entre a aptidão e vocação do trabalhador e demandas psicofisiológicas do trabalho (Abade, 2006). Com a regulamentação da Psicologia em 1962, a área obteve caráter clínico e, em função de legislações educativas da época, que incluíram o Aconselhamento Vocacional como obrigatórios para estudantes de primeiro e segundo grau (Lei $n^{\circ} 5.692 / 71$ ), enfatizou-se o aconselhamento de estudantes de ensino médio, ideia prevalente até os dias atuais (Duarte, 2013).

Conceituada como processo de facilitação à escolha e construção da trajetória profissional, as intervenções em Orientação Profissional e de Carreira podem utilizar diversas estratégias, de acordo com as necessidades do cliente, tais como orientação, para identificar e ajustar o perfil vocacional, educação profissional, com o intuito de promover o desenvolvimento profissional, e o aconselhamento de careira, para traçar projetos de vida laboral, entre outras (Savickas, 2011). As intervenções em carreira podem ser necessárias em diversos momentos da vida, desde reflexões para escolha profissional de adolescentes até preparação para aposentadoria (Melo-Silva, Lassance, \& Soares, 2004), e tem em seus objetivos compreender as variáveis que interferem na tomada de decisão, podendo lançar mão da exploração e mensuração dos objetivos do cliente comparando-os com grupos semelhantes em relação a habilidades, interesses e traços de personalidade (Savickas, 2015).

Nesse sentido, o uso de instrumentos de medidas psicológicas pode se tornar uma das estratégias adotadas pelos orientadores profissionais para facilitar a identificação de variáveis relacionadas ao contexto da carreira. Importante destacar que o uso de instrumentos psicológicos em Orientação Profissional e de Carreira se faz presente desde o surgimento do campo, inicialmente com o foco de simples ajustamento de perfil, sendo que ao longo dos anos buscou-se atentar 
para processos avaliativos especializados, sustentados por bases teóricas sólidas e acompanhando as transformações sociais (Sparta, Bardagi, \& Teixeira, 2006). Assim, muda-se o foco do instrumento utilizado como um fim (avaliação centrada no resultado da testagem) e passa-se a compreendê-lo e utilizá-lo como um meio (avaliação centrada no processo). Desse modo, há indicação de que os resultados decorrentes do uso de instrumentos psicológicos sejam articulados com as demais instâncias e informações fornecidas pelos clientes (Savickas, 2015), tais como histórias de vida e fatores contextuais e desenvolvimentais.

A preocupação com o uso e a qualidade dos instrumentos psicológicos nesse contexto é evidenciada pelos estudos que objetivaram revisar a produção científica da área com foco nos instrumentos de avaliação no âmbito nacional. Todavia tais estudos tiveram como delimitação um único construto, revisando exclusivamente instrumentos de interesses profissionais (Ambiel, Lamas, \& Melo-Silva-2016; Ambiel \& Polli, 2011; Noronha, Freitas, \& Ottati, 2003; Nunes, Okino, Noce, \& Jardim-Maran, 2008) ou um público específico, como o de universitários (Polydoro, Oliveira, Mercuri, \& Santos, 2016). Assim, tais estudos não procuraram ou se preocuparam em expandir o alcance da revisão em termos de população ou variáveis mensuradas, sendo um recorte muito específico dentro de uma área extremamente ampla.

O estudo de Ambiel e Polli (2011) foi o único na literatura nacional cujo intuito foi realizar um levantamento da produção científica brasileira a respeito da avaliação psicológica de forma ampla no contexto de Orientação Profissional e de Carreira. Embora os autores explicitem essa intenção, a pesquisa tem um forte viés ao direcionar os descritores para um construto específico (interesses profissionais) em detrimento das demais variáveis comumente abordadas e mensuradas nos processos de aconselhamento de carreira, tais como autoeficácia, maturidade para escolha, adaptabilidade, entre outras. Nesse sentido, os resultados da revisão, embora contribuam para verificar o cenário, devem ser entendidos de forma parcimoniosa em função dessa limitação metodológica.

Cabe ressaltar que a preocupação com o uso de instrumentos nesse contexto não é exclusividade dos pesquisadores brasileiros. No cenário internacional, é possível encontrar estudos de revisões sistemáticas de literatura e metaanálise com foco nos instrumentos utilizados em Orientação Profissional e de Carreira.
Há pesquisas destacando os interesses profissionais (Nye, Su, Rounds, \& Drasgow, 2017; Rounds \& Su, 2014; Su, Rounds, \& Armstrong, 2009), revisões da produção dos últimos cem anos (Sackett, Lievens, Van Iddekinge, \& Kuncel, 2017), bem como com demais construtos relacionado à vida laboral, como adaptabilidade de carreira (Rudolph, Lavigne, \& Zacher, 2017), autoeficácia e burnout (Aloe, Amo, \& Shanahan, 2014). Em suma, os estudos internacionais aplicam métodos mais rigorosos e contemplam variáveis e públicos distintos na verificação do estado da arte.

Assim, é importante sistematizar as produções da área de Orientação Profissional e de Carreira para verificar lacunas e possibilitar avanços práticos (Ambiel et al., 2017; Teixeira, Lassance, Silva, \& Bardagi, 2007). Além disso, são necessárias investigações voltadas para os instrumentos psicológicos utilizados na área (Noronha \& Ambiel, 2006), de modo a contribuir para o uso adequado da avaliação psicológica, pautada em qualidade, rigor e credibilidade (Noronha et al., 2003). Tal estudo também é importante uma vez que a área é multidisciplinar e sem definições de parâmetros formativos para os orientadores de carreira, o que leva muitos orientadores a não se sentirem seguros no momento da escolha de instrumentos para uso nos processos de Orientação Profissional e de Carreira (Antunes et al., 2009; Lassance, Melo-Silva, Bardagi, \& Paradiso, 2007; Silva, Oliveira, \& Melo-Silva, 2014).

Além disso, o Conselho Federal de Psicologia (CFP). por meio da Resolução no 9/2018, abriu uma nova possibilidade aos profissionais psicólogos permitindo o uso de fontes complementares nos processos de avaliação psicológica. Estas fontes são caracterizadas por instrumentos não psicológicos com respaldo na literatura científica em termos de funcionalidade e evidências de validade. Com a nova resolução, os profissionais continuam proibidos de utilizar instrumentos com parecer desfavorável pelo Sistema de Avaliação dos Testes Psicológicos (Satepsi), todavia podem optar por recorrer aos instrumentos disponíveis na literatura científica. Deste modo, é importante verificar quais instrumentos psicológicos e não psicológicos estão disponíveis para utilização dos profissionais que atuam em Orientação Profissional e de Carreira.

Considerando essas questões, este estudo teve por objetivo realizar uma revisão integrativa (Grant \& Booth, 2009) da produção científica nacional acerca do uso de instrumentos de avaliação psicológica no contexto da Orientação Profissional e de Carreira em um período 
de dezessete anos (2000-2017). Especificamente, buscou-se caracterizar a área em regiões do país que estão pesquisando a temática, área temática dos pesquisadores envolvidos, periódicos científicos utilizados para veiculação das informações, bem como instrumentos e construtos mais abordados nas pesquisas.

\section{Método}

\section{Estratégia de busca}

Antes da escolha de palavras-chave, realizou-se uma busca no Vocabulário de Termos em Psicologia a fim de selecionar descritores adequados e relacionados aos termos "avaliação psicológica" e "orientação profissional". Desse modo, optou-se pelos descritores "Avaliação psicológica", "Psicometria", "Medidas", "Testes Psicológicos”, "Validade do Teste”, "Construção do Teste", "Padronização do Teste”, "Orientação vocacional", "Orientação Profissional”, "Orientação de Carreira", "Escolha Profissional", "Informação Profissional", "Desenvolvimento Profissional", "Identidade Profissional" e suas correspondências no plural. Em relação aos descritores concernentes a carreira, tomou-se o cuidado de não incluir nomes de construtos para minimizar o risco de vieses na recolha dos dados. Como operadores boleanos, foram utilizados "or" entre os vocábulos da mesma área e "and" para associação entre os termos da área de avaliação psicológica e orientação de carreira. Na sequência, as buscas foram realizadas nas bases PePSIC, INDEXPSI, BVS-Psi e BVS-Salud, e com busca livre no Google Acadêmico no dia seis de junho de 2018. As bases escolhidas foram aquelas em que são indexados os artigos brasileiros e o período de busca foi delimitado a partir do ano 2000, entendendo que foi o início do período de qualificação da área de Avaliação Psicológica e que culminou na criação do Satepsi em 2001.

\section{Critérios de elegibilidade}

$\mathrm{Na}$ etapa de triagem, foram adotados os seguintes critérios de inclusão: a) artigos de pesquisa empírica publicados em periódicos científicos nacionais; b) dados coletados e publicados no Brasil; c) necessário ter utilizado testes ou instrumentos de avaliação psicológica padronizados ou em construção em contextos de Orientação Profissional e de Carreira. Além disso, os critérios de exclusão foram: a) estudos com amostras estrangeiras; b) relatos de experiência e estudos de caso; c) ensaios teóricos; d) pesquisas que utilizaram questionários ou entrevistas semiestruturadas não padronizadas; e) publicações em livros; e f) pesquisas de revisão de literatura. Em relação ao ano de publicação, estabeleceu-se como período inicial o ano 2000, considerando que foi o período em que a área de avaliação psicológica passou a receber maior atenção da categoria profissional e dos pesquisadores da área (Noronha \& Reppold, 2010). O tempo-limite de publicação para o ano 2017 foi estabelecido em função de que muitas revistas científicas ainda teriam números de edições a serem publicadas em 2018, o que levou os estudos do ano de 2018 a não serem considerados para revisão.

\section{Extração dos dados}

Os estudos que cumpriram os critérios de elegibilidade foram extraídos das bases de dados por meio do software Mendeley Desktop. Após a organização no software, os estudos passaram pela primeira triagem, por meio da leitura dos títulos e resumos. Ressalta-se que apenas para os achados na base PePSIC não houve compatibilidade para exportação ao Mendeley e que, neste caso, realizou-se o download do arquivo com títulos dos artigos e a busca de resumo foi feita individualmente para triagem. Na sequência, os artigos restantes após a primeira triagem foram lidos na íntegra, excluindo-se os que não estavam adequados aos objetivos desta pesquisa, e os elegíveis tiveram as informações descritivas e metodológicas extraídas e organizadas para a exposição dos resultados.

\section{Resultados}

Conformeexposto no Diagrama deFluxo (Figura 1), na busca inicial foram localizados 1.376 artigos oriundos de todas as bases consultadas. Após a leitura de título e resumo, foram excluídas 1.242 publicações que não atendiam aos critérios de inclusão. Dos 134 artigos restantes da triagem, 50 foram excluídos por duplicatas, resultando em 88 artigos que foram lidos na íntegra. Nessa última etapa de seleção, sete publicações não atendiam aos critérios de inclusão, pois, embora os resumos dessem margem para inclusão, na leitura completa verificou-se que não continham instrumentos de avaliação psicológica padronizados ou em processo de construção, sendo, portanto, excluídos da revisão. Assim, 79 artigos foram considerados elegíveis para este estudo. Os artigos da revisão constam na lista de referências destacados com asteriscos $\left(^{*}\right)$. 


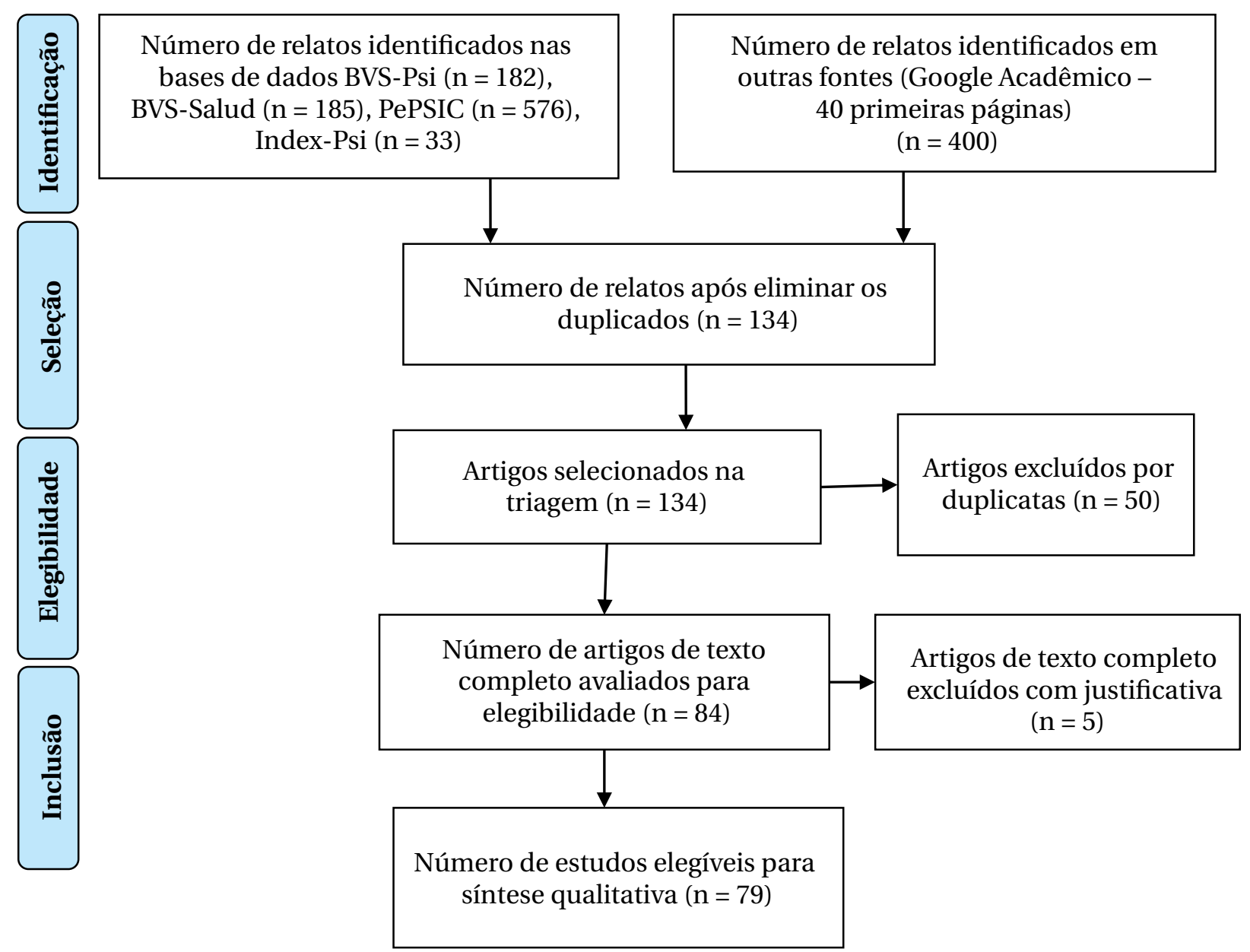

Figura 1

Diagrama de Fluxo adaptado de Moher, Liberati, Tetzlaff, Altman, \& Prisma Group (2009).

Inicialmente, buscou-se caracterizar os estudos em termos de variáveis descritivas (ano de publicação, revista, Qualis da revista, quantidade de autores e de instituições envolvidas, estado das instituições de pesquisa), com intuito de verificar o panorama geral da temática enquanto pauta de pesquisa. Em relação ao ano de publicação dos artigos, apenas no ano de 2001 não foram encontradas publicações que atendessem ao escopo desta pesquisa. A distribuição por ano ocorreu da seguinte forma: $2000(n=1)$; 2002 ( $\mathrm{n}=2) ; 2003$ ( $\mathrm{n}=3) ; 2004$ e 2005 ( $\mathrm{n}=2$ em cada); 2006 ( $\mathrm{n}=5) ; 2007(\mathrm{n}=3) ; 2008(\mathrm{n}=7) ; 2009(\mathrm{n}=5)$; $2010(\mathrm{n}=8) ; 2011(\mathrm{n}=5)$ e $2012(\mathrm{n}=6) ; 2013(\mathrm{n}=7)$; 2014 ( $n=5)$; 2015 e 2016 ( $n=8$ em cada) e 2017 ( $n=2)$.

Observa-se crescimento no número de publicações a partir de 2006 e que a maior quantidade de publicações ocorreu em 2010, 2015 e 2016, com oito artigos localizados em cada ano. Contudo a distribuição das pesquisas não ocorreu de forma linear, embora, a partir de 2002, ao menos dois artigos utilizando instrumentos de avaliação psicológica no contexto da Orientação Profissional e de Carreira foram publicados. Em relação aos autores dessas pesquisas, o número de pesquisadores envolvidos variou entre 1 e $7(M=2,9)$, sendo que a maior porcentagem foi encontrada para estudos publicados por dois autores $(41,5 \%, n=34)$, seguidos de três autores $(25,6 \%, \mathrm{n}=21) \mathrm{e}$, em menor porcentagem, estudos com $6(3,7 \%, \mathrm{n}=3)$ e $7(2,4 \%, \mathrm{n}=2)$ autores. Em relação à área de atuação dos pesquisadores, predominou a Psicologia $(92,7 \%, \mathrm{n}=76)$, mas com presença de outras áreas, como Educação Física $(4,9 \%, \mathrm{n}=4) \mathrm{e}$ Administração e Pedagogia ( $1,2 \%, \mathrm{n}=1$ em cada).

No que concerne às instituições envolvidas, apenas $6,1 \%(n=5)$ dos artigos elegíveis contou com participação de pesquisadores internacionais em coautoria. Ao analisar as instituições brasileiras nas publicações, 
verifica-se que os números variaram de 1 a $9(\mathrm{M}=1,58)$, considerando que alguns autores relataram vínculo com mais de uma instituição, sendo que foram mais frequentes publicações oriundas de uma única instituição $(58,5 \%, \mathrm{n}=48)$, seguidas de pesquisas com parcerias de duas instituições $(29,3 \%, n=24)$. Foram analisados os estados brasileiros das instituições de ensino envolvidas nas pesquisas, sendo encontradas publicações com autores de 14 estados. O maior número de publicações foi de pesquisadores das regiões Sudeste $(64,6 \%, \mathrm{n}=60)$ e Sul $(19,4 \%, \mathrm{n}=18)$. Em menor porcentagem apareceram os estudos oriundos das regiões Centro-Oeste $(8,7 \%, \mathrm{n}=8)$ e Nordeste $(7,6 \%, \mathrm{n}=7)$, e a região Norte contabilizou apenas uma publicação no período avaliado $(1,1 \%, \mathrm{n}=1)$.

Em relação aos participantes dos estudos, o tamanho amostral variou entre 8 e $6.460(\mathrm{M}=452,89)$, totalizando 35.778 respondentes. Foram predominantes pesquisas com estudantes de Ensino Médio (39,2\%, $\mathrm{n}=31$ ), estudantes universitários de diversos cursos $(22,8 \%$, $\mathrm{n}=18$ ) e trabalhadores de setores primário, secundário e terciário $(20,3 \%, n=16)$. Houve ainda estudos que abordaram discentes de ensino fundamental ao superior $(8,9 \%, \mathrm{n}=7)$ e exclusivos com estudantes de pós-graduação $(2,5 \%, n=2)$. Em menor quantidade, apareceram estudos com públicos específicos, como atletas $(3,8 \%$, $\mathrm{n}=3$ ) soldados e bailarinos $(1,3 \%, \mathrm{n}=1$ respectivamente). Ao analisar apenas o tipo de instituição de ensino nas quais houve captação de amostra de estudantes, os resultados foram equilibrados, com participantes oriundos de instituições públicas e privadas ( $34,2 \%, n=27)$, exclusivamente públicas $(16,5 \%, \mathrm{n}=13)$ e exclusivamente privada $(16,5 \%, \mathrm{n}=13)$. Na sequência, analisaram-se as revistas utilizadas como meio de divulgação das pesquisas, e os resultados são apresentados na Tabela 1.

Tabela 1

Revistas que publicaram os artigos elegíveis.

\begin{tabular}{lccc}
\hline \multicolumn{1}{c}{ Revista } & $\mathrm{f}$ & $\%$ & Qualis \\
\hline $\begin{array}{l}\text { Revista Brasileira de } \\
\text { Orientação Profissional }\end{array}$ & 21 & 25,6 & $\mathrm{~A} 2$ \\
Avaliação Psicológica & 13 & 16,9 & $\mathrm{~A} 2$ \\
Psico-USF & 6 & 7,6 & $\mathrm{~A} 2$ \\
$\begin{array}{l}\text { Revista Psicologia: } \\
\text { Organizações e Trabalho }\end{array}$ & 5 & 6,3 & $\mathrm{~A} 2$ \\
$\begin{array}{l}\text { Interação em Psicologia } \\
\text { Estudos e Pesquisas em }\end{array}$ & 3 & 3,8 & $\mathrm{~B} 2$ \\
Psicologia & 3 & 3,8 & $\mathrm{~A} 2$ \\
\hline
\end{tabular}

continua... ...continuação

\begin{tabular}{|c|c|c|c|}
\hline Revista & $\mathrm{f}$ & $\%$ & Qualis \\
\hline Estudos de Psicologia (Natal) & 3 & 3,8 & $\mathrm{~A} 1$ \\
\hline $\begin{array}{l}\text { Estudos de Psicologia } \\
\text { (Campinas) }\end{array}$ & 2 & 2,5 & Al \\
\hline Psicologia: Ciência e Profissão & 2 & 2,5 & A2 \\
\hline $\begin{array}{l}\text { Revista Brasileira de Ciência e } \\
\text { Movimento }\end{array}$ & 2 & 2,5 & B2 \\
\hline Paideia & 2 & 2,5 & Al \\
\hline Boletim de Psicologia & 2 & 2,5 & B2 \\
\hline $\begin{array}{l}\text { Psic: Revista de Psicologia da } \\
\text { Vetor Editora }\end{array}$ & 2 & 2,5 & $\mathrm{~N} / \mathrm{C}$ \\
\hline Psicologia: Reflexão e Crítica & 2 & 2,5 & Al \\
\hline Psicologia em Estudo & 1 & 1,3 & Al \\
\hline $\begin{array}{l}\text { Estudos Interdisciplinares em } \\
\text { Psicologia }\end{array}$ & 1 & 1,3 & B2 \\
\hline $\begin{array}{l}\text { Revista Psicologia Escolar e } \\
\text { Educacional }\end{array}$ & 1 & 1,3 & A2 \\
\hline Fractal: Revista de Psicologia & 1 & 1,3 & B1 \\
\hline $\begin{array}{l}\text { Arquivos Brasileiros de } \\
\text { Psicologia }\end{array}$ & 1 & 1,3 & A2 \\
\hline $\begin{array}{l}\text { Revista Brasileira de Terapias } \\
\text { Cognitivas }\end{array}$ & 1 & 1,3 & B2 \\
\hline $\begin{array}{l}\text { Revista Brasileira de } \\
\text { Psicologia do Esporte }\end{array}$ & 1 & 1,3 & B4 \\
\hline $\begin{array}{l}\text { Revista Psicologia: Teoria e } \\
\text { Prática }\end{array}$ & 1 & 1,3 & A2 \\
\hline Psicologia: Ensino e Formação & 1 & 1,3 & B5 \\
\hline Revista de Psicologia da IMED & 1 & 1,3 & B3 \\
\hline Psicologia Argumento & 1 & 1,3 & B2 \\
\hline Total & 79 & 100 & \\
\hline
\end{tabular}

Nota: Considerou-se a classificação Qualis Periódicos do Quadriênio 2013-2016 na área de Psicologia (Plataforma Sucupira); N/C = não constam informações.

Evidencia-se que as maiores frequências apareceram para as duas principais revistas das áreas analisadas nesta pesquisa, sendo a Revista Brasileira de Orientação Profissional, editada pela Associação Brasileira de Orientação Profissional (Abop), e a Revista Avaliação Psicológica, editada pelo Instituto Brasileiro de Avaliação Psicológica (Ibap). De modo geral, as publicações foram realizadas em revistas de psicologia e em periódicos avaliados com bons índices de qualidade pela Coordenadoria de Aperfeiçoamento de Pessoal do Ensino Superior (Capes). Após as análises descritivas dos estudos e do campo de interesse, foram avaliados os instrumentos utilizados nas pesquisas, sendo localizados 69 instrumentos diferentes. A Tabela 2 apresenta os instrumentos que apareceram com frequência mínima de ao menos dois estudos. 
Tabela 2

Frequência e situação dos instrumentos utilizados.

\begin{tabular}{lcc}
\hline \multicolumn{1}{c}{ Instrumento } & f & Satepsi (06/2018) \\
\hline Escala de Aconselhamento Profissional & 14 & Favorável \\
Questionário de Busca Autodirigida (SDS) & 12 & Favorável \\
Teste de Fotos de Profissões (BBT-Br) & 10 & Favorável \\
Escala de Autoeficácia para Atividades Ocupacionais (EAAOc) & 4 & Não consta \\
Avaliação dos Tipos Profissionais de Holland (ATPH) & 3 & Não consta \\
Bateria de Provas de Raciocínio (BPR-5) & 3 & Favorável \\
Escala de Entrincheiramento na Carreira & 3 & Não consta \\
Levantamento de Interesses Profissionais (LIP) & 3 & Não consta \\
Escala de Afetos Zanon (EAZ) & 2 & Não consta \\
Escala de Autoeficácia para Escolha Profissional (EAE-EP) & 2 & Favorável \\
Escala de Comprometimento com a Carreira & 2 & Não consta \\
Escala de Maturidade para Escolha Profissional (EMEP) & 2 & Favorável \\
Escalas de Exigência e Responsividade & 2 & Não consta \\
Inventário de Habilidades Sociais (IHS) & 2 & Favorável \\
Inventários Beck de Ansiedade e Depressão & 2 & Favorável \\
Questionário Fatorial de Personalidade (16P) & 2 & 2 \\
Inventário Tipológico de Interesses Profissionais (ITIP-156/96) & Desfavorável \\
Quantidade de instrumentos que apareceram apenas em uma publicação & 54 & Não consta \\
\hline
\end{tabular}

Nota: Instrumentos que apareceram apenas uma vez nas publicações: Basic Adlerian Scales of Interpersonal Styles (BASIS-A); Bateria Fatorial de Personalidade (BFP); Career Development Self-Efficacy Inventory (CD-SEI) - versão brasileira; Escala de Aspiração; Escala de Atitudes em relação à Escolha Profissional; Escala de Atitudes Frente a Estilos de Liderança; Escala de autoeficácia no Aconselhamento de carreira; Escala de Autoeficácia para bailarinos (Aebai); Escala de Avaliação de Qualidade de Vida no Trabalho; Escala de Características de Atividades Profissionais (Ecap); Escala de Comportamentos Proativos nas Organizações (ECPO); Escala de Comprometimento Organizacional; Escala de Critérios para Decisão Profissional; Escala de Efetividade no Trabalho de Cursos de Mestrado e Doutorado; Escala de Estilos de Pensar e Criar; Escala de Estilos Parentais; Escala de Generatividade; Escala de Indecisão Profissional; Escala de Indecisão vocacional; Escala de Instabilidade de Metas; Escala de Intenções Comportamentais de Permanência na Organização (EICPO); Escala de Interesses por Áreas da Psicologia (EIAPsi); Escala de Motivos para Evasão do Ensino Superior (M-ES); Escala de Preferências por Objetos Ocupacionais; Escala de Reação aos Procedimentos Instrucionais e Reação ao Desempenho do Tutor; Escala de Satisfação Acadêmica Universitária; Escala de Satisfação no Trabalho (EST); Escala de Suporte à Aprendizagem no Ambiente de Trabalho; Escala Fatorial de Socialização; Escalas de Exploração Vocacional; Escalas Fatoriais de Neuroticismo, Extroversão e Abertura à Experiência; Instrumento de Interesse por Finanças; Inventário de Interesses Angelini; Inventário de Levantamento de Dificuldades da Decisão Profissional (IDDP); Inventário de perspectiva temporal; Inventário dos 16 Fatores de Personalidade (16FP); Inventário Fatorial de Personalidade; Inventários de Percepção de Suporte Familiar (IPSF); Inventários de Sintomas de Stress para Adultos de Lipp (ISSL); Marcadores do Big Five; Matrizes Progressivas de Raven; Myers-Briggs Type Indicator (MBTI); Procedimento de Desenhos de Profissionais com Estórias; Questionário de Burnout para Atletas; Questionário de Educação à Carreira; Questionário de Orientação de Metas (TEOSQ); Questionário de Saúde Geral (QSG-12); Questionário de Vivências Acadêmicas (QVA); Servant Leadership Questionnaire (SLQ); Teste de Associação Implícita; Teste de inteligência não verbal (Forma A); Instrumento de Avaliação da Qualidade de Vida da Organização Mundial de Saúde (WHOQOL-Bref).

Verifica-se que, apesar da grande quantidade de instrumentos, apenas três foram utilizados com maior frequência nas pesquisas e que os demais apareceram com menor intensidade na literatura. Dos 69 instrumentos encontrados, apenas 17 (24,28\%) constaram em dois estudos ou mais, enquanto $52(75,72 \%)$ foram utilizados em apenas um estudo. Em relação aos instrumentos que apareceram com frequência mínima de dois estudos, a maioria tem aprovação do Satepsi para uso dos psicólogos. Na sequência, foram investigados os construtos mensurados pelos instrumentos encontrados nos estudos. Os resultados são apresentados na Tabela 3. 
Tabela 3

Construtos mensurados pelos instrumentos identificados.

\begin{tabular}{lc}
\hline \multicolumn{1}{c}{ Construto } & $\mathrm{f}$ \\
\hline Interesses profissionais & 13 \\
Personalidade & 9 \\
Autoeficácia & 5 \\
Comportamento organizacional & 5 \\
Decisão/indecisão profissional & 4 \\
Vivências acadêmicas & 4 \\
Depressão, ansiedade e estresse & 3 \\
Influências parentais & 3 \\
Inteligência & 3 \\
Qualidade de vida & 3 \\
Transição de carreira & 3 \\
Atitudes & 2 \\
Liderança & 2 \\
Satisfação com o trabalho & 2 \\
Afetos & 1 \\
Bournout & 1 \\
Criatividade & 1 \\
Evasão & 1 \\
Generatividade & 1 \\
Habilidades sociais & 1 \\
Maturidade & 1 \\
Perspectiva temporal & \\
Total & 1 \\
\hline & 1 \\
\hline & 1 \\
\hline &
\end{tabular}

Os resultados indicaram que os interesses profissionais foram o construto mais investigado, seguido de personalidade e da autoeficácia em seus diferentes domínios. Em menor frequência, apareceram construtos associados a temáticas mais específicas, como criatividade, generatividade, habilidades sociais e perspectiva temporal. Por fim, buscou-se verificar se os artigos continham descrição de propriedades psicométricas ou se buscavam evidências de validade para os instrumentos utilizados. De modo geral, 39,2\% ( $\mathrm{n}=31$ ) das publicações não tinham esse objetivo explícito, enquanto a maioria $(62,4 \% ; n=48)$ dos estudos trazia como objetivo apresentar novas informações sobre as propriedades psicométricas dos instrumentos, apresentando uma ou mais evidências de validade.

Entre as evidências de validade expostas nos artigos, predominaram as com base na estrutura interna, totalizando 29 estudos $(36,7 \%)$, seguidos por investigações de validade com base no conteúdo $(10,2 \%, \mathrm{n}=8)$ e de validade convergente ( $6, n=7,9 \%)$. Houve ainda pesquisas que buscaram evidências de validade de critério $(3,8 \%, \mathrm{n}=3)$ e aquelas que investigaram a validade de construto, validade preditiva e validade concorrente $(1,2 \%, \mathrm{n}=1$ em cada). Ressalta-se que as nomenclaturas das evidências de validade utilizada nesta revisão foram de acordo com o relato e nome dado pelos autores para os tipos de evidência de validade.

\section{Discussão}

Este estudo teve como objetivo realizar uma revisão integrativa (Grant \& Booth, 2009) da produção científica nacional acerca do uso de instrumentos de avaliação psicológica no contexto da Orientação Profissional e de Carreira. Justifica-se pelo fato de que produções de levantamento do cenário têm sido focadas em construtos, populações ou periódicos específicos (Ambiel, et al., 2016; Noronha et al., 2003; Nunes et al., 2008; Polydoro et al., 2016) ou com viés na busca dos materiais (Ambiel \& Polli, 2011). Além disso, ao considerar que o uso de instrumentos de mensuração está presente desde o surgimento da área de Orientação Profissional e de Carreira (Sparta et al., 2006), é necessário investigar o cenário atual de desenvolvimento de instrumentais utilizados pelos orientadores profissionais e o investimento em pesquisas nesta área.

Em relação à distribuição de publicações ao longo dos anos, os resultados vão ao encontro aos achados por outros autores (Ambiel \& Polli, 2011; Noronha \& Ambiel, 2006; Teixeira et al., 2007). O crescimento de publicações a partir do ano de 2003 pode estar relacionado com a maior preocupação e produção que a área de avaliação psicológica recebeu por parte dos pesquisadores da área em conjunto com o Ibap, culminando com a criação do Satepsi (Noronha \& Reppold, 2010) e com o surgimento de revistas especializadas nessa mesma época (Ambiel \& Polli, 2011). Assim, o aumento da quantidade de periódicos científicos pode ter contribuído para o crescimento de divulgação de conhecimento da área. 
Sobre a autoria dos artigos, evidenciou-se uma predominância de estudos realizados por pesquisadores do estado de São Paulo e do Rio Grande do Sul, sendo que pode ser estabelecida uma relação com a questão de que estes estados abrigam instituições de pesquisas focadas nas temáticas de avaliação psicológica e de Orientação Profissional e de Carreira, assim como maior número de programas de pós-graduação stricto sensu, principais responsáveis pelo desenvolvimento científico no país. Cabe destacar que, embora de forma discreta, outras regiões do país começaram a produzir e divulgar conhecimento na temática, diferentemente de outros achados (Ambiel \& Polli, 2011; Noronha \& Ambiel, 2006). Assim, acredita-se que há uma tendência de estudos realizados levando em consideração as variáveis locais, de modo a permitir medidas psicometricamente justas e a elaboração de normas referenciadas por espaços geográficos.

Ainda sobre a autoria dos estudos, é relativamente baixa a parceria com instituições e pesquisadores internacionais, bem como de cooperação interinstitucional nacional. Assim, apesar da importância de respeitar a singularidade de cada cientista na produção do conhecimento (Duarte, 2013), parcerias entre os pesquisadores facilitariam a ampliação e o avanço da área de Orientação Profissional e de Carreira. Essas cooperações podem contribuir também para que regiões em que a área não é tão desenvolvida possam adquirir bases sólidas de sistematização e aperfeiçoamento das práticas, contribuindo para a formação local do uso de instrumentos psicológicos nos processos de aconselhamento de carreira. Cabe ressaltar que os pesquisadores da área estão buscando responder a essa questão, sendo que, em 2016, foi criado o Grupo de Trabalho Carreiras na Associação Nacional de Pesquisas e Pós-Graduação em Psicologia (ANPEPP), tendo entre seus objetivos promover o intercâmbio e cooperação entre os centros de pesquisas.

Sobre o os participantes das pesquisas, os resultados corroboram com a ideia de que a área tem focado em estudantes do ensino médio (Duarte, 2013), uma vez que prevaleceram estudos com essa população. Todavia pode-se perceber que novas tendências estão surgindo por meio dos estudos que abordaram populações não tão usuais, como trabalhadores de diversos ramos, atletas, soldados, bailarinos e estudantes de pós-graduação. Esse dado pode ser um indicativo de que há um esforço inicial para que a área não esteja associada exclusivamente com o campo da educação e começando a fazer intersecções com áreas como Psicologia do Trabalho e Organizacional e Psicologia do Esporte, indo ao encontro de avanços necessários citados por Ambiel, Campos e Campos (2017).

No que tange aos instrumentos encontrados nesta pesquisa, os resultados mostram que, apesar do grande número, poucos são os que de fato estão disponíveis para o uso de orientadores profissionais psicólogos com parecer favorável do Satepsi. Todavia, considerando a Resolução no 9/2018 (CFP), a partir deste ano, é possível que o profissional opte por utilizar pelos instrumentos não psicológicos como fonte de informação complementar. Nessa direção, é ainda mais necessário o investimento na formação dos profissionais para que consigam avaliar as propriedades psicométricas destes instrumentos e ponderar pela sua utilização ou não. A possibilidade de utilização destes instrumentos permite superar uma lacuna apontada por Ambiel et al. (2016), que indicaram uma grande quantidade de instrumentos utilizados em pesquisas contribuindo para a construção de saberes, mas sem uma possível aplicação prática por parte dos psicólogos.

$\mathrm{O}$ alto número de instrumentos disponíveis na literatura sem submissão ao Satepsi leva a dois questionamentos: 1) instrumentos ditos psicológicos que mensuram construtos tradicionais no contexto da orientação profissional e de carreira (por exemplo: interesses profissionais) devem ser restritos a psicólogos?; e 2) o que define se os construtos relativos à carreira são de fato variáveis psicológicas? A primeira questão leva diretamente ao ponto da multidisciplinaridade envolvida no campo. Ao considerar que os profissionais que atuam como orientadores de carreira são oriundos de diversas áreas, não é possível garantir que já não ocorra o uso de instrumentos publicados em artigos ou outros meios, tanto por orientadores com formação em outras áreas como por aqueles com formação em Psicologia e, portanto, submetidos aos regulamentos específicos do CFP.

Para responder à segunda questão, toma-se como exemplo o caso dos interesses profissionais que apareceram como construto mais investigado. Diversas são as possibilidades de avaliar o padrão de preferências profissionais de uma pessoa, tal como evidenciado pela quantidade de instrumentos encontrados nesta pesquisa. Ao focar em instrumentos que mensuram interesses de forma ateórica ou em seus níveis básicos a partir de descrições ocupacionais, não há motivos plausíveis que justifiquem 
considerar o construto como psicológico. O contrário acontece para o caso do instrumento Questionário de Busca Autodirigida, que tem aporte teórico de personalidade de Holland, assim como o Teste de Fotos de Profissões (BBT-Br), baseado na teoria pulsional de Szondi, demandando interpretações mais complexas do que simplesmente indicar áreas de preferências, justificando um possível direcionamento psicológico.

Ainda sobre os instrumentos e construtos que eles avaliam, os resultados corroboram com outros estudos que apontam que os interesses profissionais são os mais investigados e utilizados na prática profissional (Ambiel \& Polli, 2011; Ambiel, et al., 2016; Noronha et al., 2003; Nunes et al., 2008). Entretanto foi possível perceber o surgimento de pesquisas abordando construtos que nem sempre são associados diretamente ao contexto de orientação profissional e de carreira. Há pesquisas que articularam variáveis de carreira com saúde mental por meio de investigações com depressão, ansiedade e estresse, bem como fazendo interlocuções com a Psicologia Positiva (qualidade de vida, afetos). Desse modo, acredita-se que a carreira tem sido compreendida como um dos componentes da vida do indivíduo, devendo ser articulado com outras esferas que não apenas o trabalho (Savickas, 2015).

Considerando a importância de prezar pela qualidade psicométrica dos instrumentos utilizados (Ambiel et al., 2016; Noronha et al., 2003), foi possível constatar que nem todos os pesquisadores têm em seus estudos o objetivo de buscar evidências de validade e que alguns desconhecem os conceitos psicométricos referindo-se a validade de construto, sendo que toda evidência que se busca é de construto. Dentre os estudos que apresentaram esse objetivo, predominaram aqueles com foco na estrutura interna e de evidências de validade com base no conteúdo. Esse resultado pode estar associado com o fato de que muitos dos artigos encontrados tratavam de processos de construção de instrumentos, reforçando a ideia da área de orientação profissional e de carreira como profícua para o desenvolvimento de instrumentos (Sparta et al., 2006) e, por outro lado, evidenciando a necessidade de que hajam mais estudos com os instrumentos já existentes.

Assim, esta revisão integrativa acerca do uso de instrumentos psicológicos em orientação profissional e de carreira permitiu traçar um panorama da área e encontrar avanços e lacunas a serem superadas. Percebe-se que o campo tem avançado em termos de alcance de populações, associando variáveis nem sempre consideradas em pesquisas sobre carreira e com surgimento de pesquisadores de regiões não pertencentes ao eixo Sul-Sudeste interessados na temática. Além disso, a quantidade de instrumentos utilizados em investigações no contexto profissional tem sido expressiva, fato que justifica ainda mais a necessidade de compreender como o uso tem sido realizado a fim de que sejam incentivados estudos que objetivem oferecer instrumentos com qualidade psicométrica, bem como maior investimento na formação em relação às competências e habilidades para a utilização dos instrumentos.

Espera-se que este estudo contribua com as investigações do campo de avaliação psicológica e sua interlocução com a área de orientação profissional e de carreira, favorecendo que novos problemas de pesquisas possam ser aventados e propiciem o avanço técnico e científico da área. Sugere-se que investigações futuras sanem as limitações desta pesquisa, que se limitou a investigar publicações apenas de periódicos científicos e pesquisas empíricas. Além disso, as publicações referentes ao ano de 2017 podem não refletir a realidade, tendo em vista que muitas revistas científicas estão com suas edições atrasadas. Assim, recomenda-se a realização de revisões sistemáticas que considerem também estudos que não estão disponíveis em periódicos científicos, tais como teses e dissertações ou, além disso, que verifiquem o uso desses instrumentos no contexto prático do orientador profissional com revisões de relatos de experiência.

Ainda que não tenha sido intenção realizar uma revisão sistemática, foram adotados procedimentos rigorosos para esta investigação, tal como parcimônia na escolha de descritores, extração dos dados em todas as bases no mesmo dia, organização dos dados de acordo com o sugerido pelo grupo Prisma, para que os resultados pudessem ser menos enviesados possível. Em futuros estudos, sugere-se a aplicação de critérios de análise de qualidade dos relatos e de risco de vieses dos estudos elegíveis. Todavia é de fundamental importância que estudos desse tipo continuem sendo realizados tanto em termos de resgate e acompanhamento histórico da área como para que haja um posicionamento crítico acerca dos avanços e problemas a serem superados. 


\section{Referências}

*Artigos analisados na revisão

Abade, F. L. (2005). Orientação profissional no Brasil: Uma revisão histórica da produção científica. Revista Brasileira de Orientação Profissional, 6(1), 15-24. http://pepsic.bvsalud.org/pdf/rbop/v6n1/v6nla03.pdf

*Abdalla, M. M., Azevedo, C. E. F., Gonzalez, R. K., Oliveira, L. G. L., \& Nippes, R. C. (2012). Finanças nos cursos de administração: Análise do interesse pessoal discente. Revista Brasileira de Orientação Profissional, 13(1), 87-101. http://www.redalyc.org/pdf/2030/203023770010.pdf

*Almeida, S. P. D., \& Faro, A. (2016). Tradução, adaptação e validação do Servant Leadership Questionnaire (Escala de Liderança Servidora). Revista Psicologia Organizações e Trabalho, 16(3), 285-297. https://orcid.org/10.17652/rpot/2016.3.11929

Aloe, A. M., Amo, L. C., \& Shanahan, M. E. (2014). Classroom management self-efficacy and burnout: A multivariate meta-analysis. Educational Psychology Review, 26(1), 101-126. https://orcid.org/10.1007/s10648-013-9244-0

*Ambiel, R.A. M. (2015). Construção da escala de motivos para evasão do ensino superior. Avaliação Psicológica, 14(1), 41-52. https:// orcid.org/10.15689/ap.2015.1401.05

Ambiel,R.A.M.,Campos, M.I.,\&Campos,P.P.T.V.Z. (2017).Análisedaprodução científica brasileiraemorientaçãoprofissional: Um convite a novos rumos. Psico-USF, 22(1), 133-145. https://orcid.org/10.1590/1413-82712017220112

Ambiel, R. A. M., Lamas, K. C. A., \& Melo-Silva, L. L. (2016). Avaliação dos interesses profissionais no Brasil: revisão da produção científica. Avaliação Psicológica, 15(esp.), 1-9. https://orcid.org/10.15689/ap.2016.15ee.01

*Ambiel, R. A. M., \& Martins, G. H. (2016). Interesses profissionais expressos e inventariados de estudantes de psicologia: Implicaçõesparaaformação. PsicologiaEnsino\&Formaç̧ão, 7(1),5-17.https://orcid.org/10.21826/2179-5800201671517

*Ambiel, R. A. M., \& Noronha, A. P. P. (2011). Construção dos itens da escala de autoeficácia para escolha profissional. Psico-USF, 16(1), 23-32. http://www.redalyc.org/pdf/4010/401036084004.pdf

Ambiel, R. A. M., \& Polli, M. F. D. (2011). Análise da produção científica brasileira sobre avaliação psicológica em orientação profissional. Estudos Interdisciplinares em Psicologia, 2(1), 103-121. http://pepsic.bvsalud.org/pdf/eip/v2n1/a08.pdf

Antunes, J., Melo-Silva, L. L., Taveira, L. F. M. C., Talavera, E. R., Soto, N. M., Ferrer-Sama, P., \& Hiebert, B. (2009). Competências do orientador profissional brasileiro. Revista Espanhola de Orientação e Psicopedagogia, 20(2), 99-108. http://www.redalyc.org/pdf/3382/338230782002.pdf

*Baiocchi, A. C., \& Magalhães, M. (2004). Relações entre processos de comprometimento, entrincheiramento e motivação vital em carreiras profissionais. Revista Brasileira de Orientação Profissional, 5(1), 63-69. http://pepsic.bvsalud.org/pdf/rbop/v5n1/v5nla06.pdf

*Balbinotti, M. A. A, \& Tétreau, B. (2006). Questionário de educação à carreira: Propriedades psicométricas da versão brasileira e comparação transcultural. Revista Brasileira de Orientação Profissional, 7(2), 49-67. http://pepsic. bvsalud.org/pdf/rbop/v7n2/v7n2a06.pdf

*Balbinotti, M. A. A,Valentini, F, \& Oliveira Cândido, M. D. (2006). Níveis de interesses profissionais em soldados do exército brasileiro. Revista Brasileira de Orientação Profissional, 7(1), 23-36. http://www.redalyc.org/pdf/2030/203016899004.pdf

*Barbosa, A. J. G., \& Lamas, K. C. A. (2012). A orientação profissional como atividade transversal ao currículo escolar. Estudos de Psicologia, 17(3), 461-468. http://www.redalyc.org/pdf/261/26125519015.pdf

*Barbosa, S. D. C., Melo, R. L. P. D., Medeiros, M. U. F. D., \& Vasconcelos, T. M. (2010). Perfil de bem-estar psicológico em profissionais de limpeza urbana. Revista Psicologia Organizações e Trabalho, 10(2), 54-66. http://pepsic.bvsalud.org/pdf/rpot/v10n2/v10n2a05.pdf

*Bardagi, M. P., Teixeira, M. A. P., Lassance, M. C. P., \& Janeiro, I. N. (2015). Propriedades psicométricas da versão brasileira do Inventário de Perspectiva Temporal para adolescentes. Avaliação Psicológica, 14(1), 1-8.

*Bartholomeu, D., Machado, A. A., Spigato, F., Bartholomeu, L. L., Cozza, H. F., \& Montiel, J. M. (2010). Traços de personalidade, ansiedade e depressão em jogadores de futebol. Revista Brasileira de Psicologia do Esporte, 3(1), 98-114. http:// pepsic.bvsalud.org/pdf/rbpe/v3n1/v3nla07.pdf

*Bartholomeu, D., Nunes, C. H. S. D. S., \& Machado, A. A. (2008). Traços de personalidade e habilidades sociais em universitários. PsicoUSF, 13(1), 41-50. http://pepsic.bvsalud.org/pdf/psicousf/v13n1/v13n1 a06.pdf 
*Bemfica, T. E. B., Fagundes, L. H. S., Pires, D. A., \& Costa, V. T. (2013). Efeito da temporada sobre a percepção da síndrome de burnout por atletas de futebol profissional. Revista Brasileira de Ciência e Movimento, 21(4), 142-150. https://orcid.org/10.18511/0103-1716/rbcm.v21n4p142-150

Brasil. (1971). Lei no 5.692 de 11 de agosto de 1971. Fixa Diretrizes e Bases para o ensino de $1^{\circ} \mathrm{e} 2^{\circ}$ graus, e dá outras providências. Revogada pela Lei no 9.394, de 20.12.1996. Brasília, DF. http://www.planalto.gov.br/ccivil_03/Leis/L5692.htm

*Brito, F. D. S., \& Magalhães, M. D. O. (2017). Avaliação de ambientes ocupacionais: construção do Inventário de Classificação Ocupacional. Revista Brasileira de Orientação Profissional, 18(1), 93-104. https://orcid.org/10.26707/1984-7270/2017v18n1p93

*Bueno, J. M. H., Lemos, C. D., \& Tomé, F. A. M. F. (2004). Interesses profissionais de um grupo de estudantes de psicologia e suas relações com inteligência e personalidade. Psicologia em Estudo, 9(2), 271-278. http://www.scielo.br/pdf/pe/v9n2/v9n2a13

${ }^{*}$ Cahú, R. A. G., Santos, A. C. O. D., Pereira, R. C., Vieira, C. J. L., \& Gomes, S. A. (2014). Estresse e qualidade de vida em residência multiprofissional em saúde. Revista Brasileira de Terapias Cognitivas, 10(2), 76-83. https://orcid.org/10.5935/1808-5687.20140013

*Caruzzo, N. M., Nascimento-Junior, J. R. A., Vieira, J. L. L., \& Vieira, L. F. (2013). Orientação de metas no contexto do vôlei de praia paranaense. Revista Brasileira de Ciência e Movimento, 21(3), 42-50. https://orcid.org/10.18511/0103-1716/ rbcm.v21n3p42-50

*Castelo, L. B., \& Luna, I. N. (2012). Crença de autoeficácia eidentidade profissional: Estudo com professores do ensino médio. Psicologia Argumento, 30(68), 27-42. https://periodicos.pucpr.br/index.php/psicologiaargumento/ article/view/19827

${ }^{*}$ Cericatto, C., Alves, C. F. \& Patias, N. D. (2017). A maturidade para a escolha profissional em adolescentes do ensino médio. Revista de Psicologia da IMED, 9(1), 22-37. https:/ / orcid.org/10.18256/2175-5027.2017.v9i1.1487

${ }^{*}$ Coelho Junior, F. A., Abbad, G. D. S., \& Todeschini, K. C. D. L. (2005). Construção e validação de uma escala de suporte à aprendizagem no trabalho em uma instituição bancária brasileira. Revista Psicologia Organizações e Trabalho, 5(2), 167-196. http://pepsic.bvsalud.org/pdf/rpot/v5n2/v5n2a07.pdf

Conselho Federal de Psicologia. (2018). Resolução $n^{o}$ 9, de 25 de abril de 2018. Estabelece diretrizes para a realização de Avaliação Psicológica no exercício profissional da psicóloga e do psicólogo, regulamenta o Sistema de Avaliação de Testes Psicológicos - SATEPSI e revoga as Resoluções nº 002/2003, nº 006/2004 e nº 005/2012 e Notas Técnicas nº 01/2017 e 02/2017. Brasília, DF.

*Couto, G., Bartholomeu, D., \& Montiel, J. M. (2016). Estrutura interna do Myers Briggs Type Indicator (MBTI): evidência de validade. Avaliação Psicológica, 15(1), 41-48. https://orcid.org/10.15689/ap.2016.1501.05

*Del Prette, A., \& Del Prette, Z. A. P. (2003). No contexto da travessia para o ambiente de trabalho: treinamento de habilidades sociais com universitários. Estudos de Psicologia, 8(3), 413-420. http://www.scielo.br/pdf/\%0D/ epsic/v8n3/19963.pdf

Duarte, M. E. (2013). A vida da orientação na vida do século XXI: constrangimentos e desafios. Revista Brasileira de Orientação Profissional, 14(2), 155-164. http://www.redalyc.org/pdf/2030/203030931002.pdf

*Fernandes, D. C., Noronha, A. P. P., \& Ambiel, R. A. M. (2016). Análise dos itens da Escala de Aconselhamento Profissional (EAP) pelo modelo de Rasch. Interação em Psicologia, 19(3), 341-349.

${ }^{*}$ Godoy, S., \& Noronha, A. P. P. (2010). Estudo correlacional entre a Escala de Aconselhamento Profissional (EAP) e o Inventário Fatorial de Personalidade (IFP). Estudos e Pesquisas em Psicologia, 10(3), 848-864. http://pepsic.bvsalud.org/pdf/epp/v10n3/v10n3a13.pdf

*Godoy, S., Noronha, A. P. P., Ambiel, R. A. M, \& Nunes, M. F. O. (2008). Instrumentos de inteligência e interesses em orientação profissional. Estudos de Psicologia, 13(1), 75-81. http://www.redalyc.org/pdf/261/26113109.pdf

${ }^{*}$ Godoy, S., Ottati, F., \& Noronha, A. P. P. (2009). Interesse profissional e estilos de pensar e criar em estudantes de Psicologia. Boletim de Psicologia, 59(131), 191-207. http://pepsic.bvsalud.org/pdf/bolpsi/v59n131/v59n131a06.pdf

Grant, M. J., \& Booth, A. (2009). A typology of reviews: an analysis of 14 review types and associated methodologies. Health Information \& Libraries Journal, 26(2), 91-108. https://orcid.org/10.1111/j.1471-1842.2009.00848.x

*Hutz, C. S., \& Bardagi, M. P. (2006). Indecisão profissional, ansiedade e depressão na adolescência: a influência dos estilos parentais. PsicoUSF, 11(1), 65-73. http://www.scielo.br/pdf/pusf/v1ln1/v1lnla08 
*Junqueira, M. L., \& Melo-Silva, L. L. (2014). Maturidade para a escolha de carreira: estudo com adolescentes de um serviço-escola. Revista Brasileira de Orientação Profissional, 15(2), 187-199. http://www.redalyc.org/ pdf/2030/203040852009.pdf

Lassance, M. C. P., Melo-Silva, L. L., Bardagi, M. P., \& Paradiso, A. C. (2007). Competências do orientador profissional: uma proposta brasileira com vistas à formação e certificação. Revista Brasileira de Orientação Profissional, 8(1), 87-93. http://www.redalyc.org/pdf/2030/203016904007.pdf

${ }^{*}$ Leal, M. D. S., Melo-Silva, L. L., \& Teixeira, M. O. (2015). Crenças para lidar com tarefas de carreira em estudantes do ensino médio. Avaliação Psicológica, 14(1), 125-132. https://orcid.org/10.15689/ap.2015.1401.14

*Lemos, C. G. (2007). Desenhos de profissionais com estórias: Desenvolvimento e características psicodinâmicas. Revista Brasileira de Orientação Profissional, 8(2), 41-55. http://www.redalyc.org/pdf/2030/203016901005.pdf

${ }^{*}$ Magalhães, M. O. (2006). Relação entre personalidades vocacionais e estilos interpessoais. Revista Brasileira de Orientação Profissional, 7(1), 11-22. http://pepsic.bvsalud.org/pdf/rbop/v7n1/v7nla03.pdf

*Magalhães, M. O. (2008). Propriedades psicométricas da versão brasileira da Escala de Entrincheiramento na Carreira. Psico-USF, 13(1), 13-19. http://pepsic.bvsalud.org/pdf/psicousf/v13n1/v13n1a03.pdf

*Magalhães, M. O. (2013). Validade de critério da Escala de Atividades do Questionário de Busca Autodirigida. Avaliação Psicológica, 12(1), 91-99. http://www.redalyc.org/pdf/3350/335027504012.pdf

*Magalhães, M. O., Alvarenga, P., \& Teixeira, M. A. P. (2012). Relação entre estilos parentais, instabilidade de metas e indecisão vocacional em adolescentes. Revista Brasileira de Orientação Profissional, 13(1), 15-25. http://pepsic. bvsalud.org/pdf/rbop/v13n1/04.pdf

*Magalhães, M. O., \& Gomes, W. B. (2005). Personalidades vocacionais, generatividade e carreira na vida adulta. Revista Brasileira de Orientação Profissional, 6(2), 71-80. http://pepsic.bvsalud.org/pdf/rbop/v6n2/v6n2a07.pdf

*Mansão, C. S. M., Noronha, A. P. P., \& Ottati, F. (2011). Interesses profissionais: Análise correlacional entre dois instrumentos de avaliação. Revista Brasileira de Orientação Profissional, 12(2), 175-183. http://www.redalyc.org/ pdf/2030/203022103005.pdf

*Mansão, C. S. M., \&Yoshida, E. M. P. (2006). SDS - Questionário de busca auto-dirigida: Precisão e validade. Revista Brasileira de Orientação Profissional, 7(2), 67-79. http://pepsic.bvsalud.org/pdf/rbop/v7n2/v7n2a07.pdf

*Martins, L. B, \& Zerbini, T. (2015). Evidências de validade de instrumentos de reações no ensino superior à distância. Estudos e Pesquisas em Psicologia, 15(1), 116-134. http://www.redalyc.org/pdf/4518/451844503008.pdf

${ }^{*}$ Masotti, D. R., \& Noronha, A. P. P. (2016). Estudo correlacional entre interesses profissionais e autoeficácia com tecnólogos. Interação em Psicologia, 19(1), 107-117. https://orcid.org/10.5380/psi.v19i1.28920

*Meireles, E., \& Primi, R. (2015).Validity and reliability evidence for assessing holland's career types. Paidéia, 25(62), 307-315. https://orcid.org/10.1590/1982-43272562201504

Melo-Silva, L. L., Lassance, M. C. P., \& Soares, D, H, P. (2004). A orientação profissional no contexto da educação e trabalho, Revista Brasileira de Orientação Profissional, 5(2), 31-52. http://pepsic.bvsalud.org/pdf/rbop/v5n2/v5n2a05.pdf

*Melo-Silva, L. L., Noce, M. A., \& Andrade, P. P. (2003). Interesses em adolescentes que procuram orientação profissional. Psic: Revista da Vetor Editora, 4(2), 6-17. http://pepsic.bvsalud.org/pdf/psic/v4n2/v4n2a02.pdf

*Melo-Silva, L. L., Oliveira, J. C. D., \& Coelho, R. D. S. (2002). Avaliação da orientação profissional no desenvolvimento da maturidade na escolha da profissão. Psic: Revista da Vetor Editora, 3(2), 44-53. http://pepsic.bvsalud. $\mathrm{org} / \mathrm{pdf} / \mathrm{psic} / \mathrm{v} 3 \mathrm{n} 2 / \mathrm{v} 3 \mathrm{n} 2 \mathrm{a} 06 . \mathrm{pdf}$

*Menezes, I. G., \& Bastos, A. V. B. (2010). Propriedades psicométricas da escala de intenções comportamentais de permanência na organização (EICPO). Estudos e Pesquisas em Psicologia, 10(3), 800-817. http://www.redalyc. org/pdf/4518/451844633010.pdf

Moher, D., Liberati, A., Tetzlaff, J., Altman, D. G., \& Prisma Group. (2009). Preferred reporting items for systematic reviews and meta-analyses: The PRISMA statement. PLoS Medicine, 6(7). https://orcid.org/10.1371/journal.pmed.1000097

*Murgo,C. S., Andrade, R. G, \& Rozendo, K.C. (2016). Escala de preferências por objetos ocupacionais: Correlações com o Questionário de Busca Autodirigida. Revista Brasileira de Orientação Profissional, 17(2), 139-149. http://www.redalyc.org/pdf/4518/451844633010.pdf 
Noronha, A. P. P., \& Ambiel, R. A. M. (2006). Orientação profissional e vocacional: análise da produção científica. PsicoUSF, 11(1), 75-84. http://www.scielo.br/pdf/pusf/v1lnl/vllnla09

*Noronha, A. P. P., \& Ambiel, R. A. M. (2008). Estudo Correlacional entre Escala de Aconselhamento Profissional (EAP) e Self-Directed Search (SDS). Interação em Psicologia, 12(1), 21-33. https://orcid.org/10.5380/psi.v12i1.5998

*Noronha, A. P. P., Ambiel, R. A. M., Frigatto, V., \& Toledo, C. C. R. (2010). Relações entre interesses, intenções e critérios de escolha profissional. Estudos Interdisciplinares em Psicologia, 1(1), 2-25. http://pepsic.bvsalud.org/pdf/ eip/vln1/a02.pdf

Noronha, A. P. P., Freitas, F. A. D., \& Ottati, F. (2003). Análise de instrumentos de avaliação de interesses profissionais. Psicologia: Teoria e Pesquisa, 19(3), 287-291.

*Noronha, A. P. P., \& Mansão, C. S. M. (2012). Interesses profissionais e afetos positivos e negativos: estudo exploratório com estudantes de ensino médio. Psico-USF, 17(2), 323-331. http://www.redalyc.org/pdf/4010/401036090016.pdf

*Noronha, A. P. P., Mansão, C. S. M., Silva, M. A., Freitas, P. C. S, \& Pereira, G. O. A. (2013). Evidências de validade convergente-discriminante para a avaliação dos tipos profissionais de Holland (ATPH). Psicologia Ciência e Profissão, 33(1), 4-15. http://www.redalyc.org/pdf/2820/282026452003.pdf

*Noronha, A. P. P., Martins, D. D. F., Gurgel, M. G. D. A., \& Ambiel, R. A. M. (2009). Estudo correlacional entre interesses profissionais e vivências acadêmicas no ensino superior. Psicologia Escolar e Educacional, 13(1), 143-154. http://www.scielo.br/pdf/pee/v13n1/v13nla16

*Noronha,A. P.P., \&Nunes, M.F.O. (2012). Escala deAconselhamento Profissional:Análisecom estudantes de ensino médio. Fractal: Revista de Psicologia, 24(2), 405-422. http://www.periodicoshumanas.uff.br/Fractal/article/view/378/680

*Noronha, A. P. P., Pinto, L. P., \& Ottati, F. (2016). Análise fatorial confirmatória da Escala de Aconselhamento Profissional. Arquivos Brasileiros de Psicologia, 68(1), 62-71. http://pepsic.bvsalud.org/pdf/arbp/v68n1/v68n1a06.pdf

${ }^{*}$ Noronha, A. P. P., \& Ottati, F. (2010). Interesses profissionais de jovens e escolaridade dos pais. Revista Brasileira de Orientação Profissional, 11(1), 37-47. http://pepsic.bvsalud.org/pdf/rbop/v1ln1/v1lnla05.pdf

Noronha, A. P. P., \& Reppold, C. T. (2010). Considerações sobre a avaliação psicológica no Brasil. Psicologia: Ciência e Profissão, 30(Esp.), 192-201. http://www.redalyc.org/pdf/2820/282021786008.pdf

${ }^{*}$ Nunes, M. F. O., \& Noronha, A. P. P. (2008). Escala de auto-eficácia para atividades ocupacionais: Construção e estudos exploratórios. Paidéia, 18(39), 111-124. http://www.redalyc.org/pdf/3054/305423760011.pdf

*Nunes, M. F. O., \& Noronha, A. P. P. (2009). Relações entre interesses, personalidade e habilidades cognitivas: Um estudo com adolescentes. Psico-USF, 14(2), 131-141. http://pepsic.bvsalud.org/pdf/psicousf/v14n2/v14n2a02.pdf

*Nunes, M. F. O., \& Noronha, A. P. P. (2011a). Associações entre auto-eficácia para atividades ocupacionais e interesses em adolescentes. Psicologia: Reflexão e Crítica, 24(1), 1-9. http://www.scielo.br/pdf/prc/v24n1/v24n1a02

*Nunes, M. F. O., \& Noronha, A. P. P. (2011b). Escala de autoeficácia para atividades ocupacionais: Estudo da estrutura interna e precisão. Avaliação Psicológica, 10(1), 25-40. http://www.redalyc.org/pdf/3350/335027285004.pdf

Nunes, M. F. O., Okino, E. T. K., Noce, M. A., \& Jardim-Maran, M. L. C. (2008). Interesses profissionais: Perspectivas teóricas e instrumentos de avaliação. Avaliação Psicológica, 7(3), 403-414. http://www.redalyc.org/pdf/3350/335027185012.pdf

Nye, C. D., Su, R., Rounds, J., \& Drasgow, F. (2017). Interest congruence and performance: Revisiting recent meta-analytic findings. Journal of Vocational Behavior, 98, 138-151. https://orcid.org/10.1016/j.jvb.2016.11.002

*Okino, E. T. K., Noce, M. A., Assoni, R. D. F., Corlatti, C. D. T., Pasian, S. R., \& Jacquemin, A. (2003). A adaptação do BBT - Teste de fotos de profissões - para o contexto sociocultural brasileiro. Revista Brasileira de Orientação Profissional, 4(1-2), 87-96. http:// pepsic.bvsalud.org/pdf/rbop/v4n1-2/v4n1-2a08.pdf

*Okino, E. T. K., \& Pasian, S. R. (2010). Evidências de precisão e validade do Teste de Fotos de Profissões (BBT-Br). Revista Brasileira de Orientação Profissional, 11(1), 23-35. http://pepsic.bvsalud.org/pdf/rbop/v11n1/vl1nla04.pdf

*Okino, E. T. K., \& Pasian, S. R. (2015). Convergência entre interesses do SDS e inclinações motivacionais do BBT-BR no Brasil. Revista Brasileira de Orientação Profissional, 16(2), 137-148. http://www.redalyc.org/pdf/2030/203046164005.pdf

*Oliveira, M. C., Silva, B. R., Garcia, R. G., Melo-Silva, L. L., \& Teixeira, M. A. P. (2014). Escala de autoeficácia no aconselhamento de carreira: Adaptação e evidências de validade. Avaliação Psicológica, 13(3), 371-381. http://www.redalyc.org/pdf/3350/335037824009.pdf 
*Ottati, F., \&Noronha, A. P. P. (2016). Escala de Aconselhamento Profissional eTeste de Fotos de Profissões: Evidências devalidade. EstudosdePsicologia (Campinas), 33(4),655-665.https://orcid.org/10.1590/1982-02752016000400009

*Pasian, S. R., \& Jardim-Maran, M. L. C. (2008). Padrões normativos do BBT-Br em adolescentes: uma verificação da atualidade das normas disponíveis. Revista Brasileira de Orientação Profissional, 9(1), 61-74. http:/ /www.redalyc. org/pdf/2030/203016830006.pdf

*Pilati, R., Porto, J. B., \& Silvino, A. M. D. (2007). Validação de medidas de efetividade de cursos de mestrado e doutorado no trabalho. Revista Psicologia Organizações e Trabalho, 7(2), 78-94. http://pepsic.bvsalud.org/pdf/rpot/v7n2/v7n2a05.pdf

Polydoro, S. A., J.. Oliveira, K. L., Mercuri, E. N. G. S., \& Santos, A. A. A.(2016). Uso de instrumentos de avaliação na produção científica envolvendo universitários brasileiros. Avaliação Psicológica, 15, 45-55. https://doi.org/10.15689/ap.2016.15ee.05

*Primi, R., Bighetti, C. A., Munhoz, A. H., Noronha, A. P. P., Polydoro, S. A., Nucci, E. P., \& Pelegrini, M. C. K. (2002). Personalidade, interesses e habilidades: um estudo correlacional da BPR-5, LIP e do 16PF. Avaliação Psicológica, 1(1), 61-72. http://pepsic.bvsalud.org/pdf/avp/vln1/vlnla07.pdf

*Primi, R., Munhoz, A. M. H., Bighetti, C. A., Nucci, E. P., Pellegrini, M. C. K., \& Moggi, M. A. (2000). Desenvolvimento de um inventário de levantamento das dificuldades da decisão profissional. Psicologia: Reflexão e Crítica, 13(3), 451-463. http://www.scielo.br/pdf/prc/v13n3/v13n3al3

*Rabelo, A. L. A., Pilati, R., \& Porto, J. B. (2016). O Teste de Associação Implícita para avaliação da preferência profissional em psicologia. Revista Brasileira de Orientação Profissional, 17(2), 189-199. http://pepsic.bvsalud.org/ pdf/rbop/v17n2/07.pdf

Ribeiro, M. A., \& Uvaldo, M. C. C. (2007). Frank Parsons: Trajetória do pioneiro da orientação vocacional, profissional e de carreira. Revista Brasileira de Orientação Profissional, 8(1), 19-31. http://www.redalyc.org/pdf/2030/203016904002.pdf

Rounds, J., \& Su, R. (2014). The nature and power of interests. Current Directions in Psychological Science, 23(2), 98-103. https://doi.org/10.1177/0963721414522812

Rudolph, C. W., Lavigne, K. N., \& Zacher, H. (2017). Career adaptability: A meta-analysis of relationships with measures of adaptivity, adapting responses, and adaptation results. Journal of Vocational Behavior, 98, 17-34. https://doi.org/10.1016/j.jvb.2016.09.002

*Rueda, F. J. M., Ottati, F., Pinto, L. P., Lima, T. H. D., \& Bueno, J. M. D. P. (2013). Construção e validação de uma escala de avaliação da qualidade de vida no trabalho. Avaliação Psicológica, 12(1), 43-50. http://pepsic.bvsalud.org/pdf/ avp/v12n1/v12nla07.pdf

Sackett, P. R., Lievens, F., Van Iddekinge, C. H., \& Kuncel, N. R. (2017). Individual differences and their measurement: A review of 100 years of research. Journal of Applied Psychology, 102(3), 254-273. https://doi.org/10.1037/apl0000151

*Sartori, F. A., Noronha, A. P. P., \& Nunes, M. F. O. (2009). Comparações entre EAP e SDS: Interesses profissionais em alunos do ensino médio. Boletim de Psicologia, 59(130), 17-29. http://pepsic.bvsalud.org/pdf/bolpsi/v59n130/v59n130a03.pdf

Savickas, M. L. (2011). Career counseling (Theories of psychotherapy series). Washington, DC: American Psychological Association.

Savickas, M. L. (2015). Life-design counseling manual. Rootstown, OH: Author.

*Shimada, M., \& Melo-Silva, L L. (2013). Interesses profissionais e papéis de gênero: escolhas femininas no BBT-Br. Avaliação Psicológica, 12(2), 243-251. http://www.redalyc.org/pdf/3350/335027505015.pdf

*Silva, A. M. B. D., Luz, T. S. R., Afonso, R. D. M., Araújo, M. F. D., Bittencourt, I. G., Carvalho, L. D. F., \& Enumo, S. R. F. (2015). Escala de Autoeficácia para Bailarinos (AEBAI): construção e evidências de validade. Avaliação Psicológica, 14(1), 83-88. http://pepsic.bvsalud.org/pdf/avp/v14n1/v14nla10.pdf

Silva, B. R., Oliveira, M. C., \& Melo-Silva, L. L. (2014). Autoeficácia no aconselhamento de carreira: Estudo com orientadores profissionais brasileiros. Revista Brasileira de Orientação Profissional, 15(1), 5-13. http://pepsic.bvsalud.org/ pdf/rbop/v15nl/03.pdf

*Sisto, F. F, Muniz, M., Bartholomeu, D., Pasetto, N. S. V, Oliveira, A. F., \& Lopes, W. M. G. (2008). Estudo para a construção de uma escala de satisfação acadêmica para universitários. Avaliação Psicológica, 7(1), 45-55. http://pepsic.bvsalud.org/pdf/avp/v7n1/v7nla07.pdf 
*Sisto, F. F., Takahashi, L. T., \& Cecilio-Fernandes, D. (2014). Estudo da dimensionalidade da escala de comprometimento organizacional pelo modelo de Rasch. Psicologia: Teoria e Prática, 16(2), 141-155. https://doi.org//10.15348/1980-6906/psicologia.v16n2p141155

Sparta, M., Bardagi, M. P., \& Teixeira, M. A. P. (2006). Modelos e instrumentos de avaliação em orientação profissional: Perspectiva histórica e situação no Brasil. Revista Brasileira de Orientação Profissional, 7(2) 19-32. http://www.redalyc.org/pdf/2030/203016895004.pdf

Su, R., Rounds, J., \& Armstrong ,P. I. (2009). Men and things, women and people: A meta-analysis of sex differences in interests. Psychological Bulletin, 135, 859-884. https://doi.org/10.1037/a0017364

*Teixeira, M. A. P., \& Dias, A. C. G. (2011). Escalas de exploração vocacional para estudantes de ensino médio. Estudos de Psicologia (Campinas), 28(1), 89-96. https:// doi.org/10.1590/S0103-166X2011000100009

Teixeira, M. A. P, Lassance, M. C. P., Silva, B. M. B, \& Bardagi, M. P. (2007). Produção científica em orientação profissional: Uma análise da Revista Brasileira de Orientação Profissional. Revista Brasileira de Orientação Profissional, 8(2), 25-40. http://pepsic.bvsalud.org/pdf/rbop/v8n2/v8n2a04.pdf

*Valentini, F, Teodoro, M. L. M., \& Balbinotti, M. A. A. (2009). Relações entre interesses vocacionais e fatores de personalidade. Revista Brasileira de Orientação Profissional, 10(2), 57-68. http://www.redalyc.org/pdf/2030/203014923007.pdf

*Veiga, H. M. D. S., Torres, C. V., \& Bruno-Faria, M. D. F. (2013). Comportamento pró-ativo e normas sociais: validação de medidas e estudo correlacional. Revista Psicologia Organizaçães e Trabalho, 13(2), 155-170. http://pepsic.bvsalud.org/pdf/rpot/v13n2/v13n2a05.pdf

*Ventura, C. D, \& Noronha, A. P. P. (2014). Autoeficácia para escolha profissional, suporte familiar e estilos parentais em adolescentes. Avaliação Psicológica, 13(3), 317-324. http://www.redalyc.org/pdf/3350/335037824003.pdf

*Welter, G. M. R. (2007). O BBT-Teste de fotos de profissões em adultos e adolescentes. Revista Brasileira de Orientação Profissional, 8(1), 45-58. http://www.redalyc.org/pdf/2030/203016904004.pdf

*Welter, G. M. R., \& Capitão, C. G. (2009). Inclinação profissional e personalidade: Estudo de correlação entre medidas desses construtos. Psicologia: Ciência e Profissão, 29(3), 588-601. http://www.scielo.br/pdf/pcp/v29n3/v29n3a12

\section{Leonardo de Oliveira Barros}

Doutor em Psicologia. Professor adjunto do Instituto de Psicologia da Universidade Federal da Bahia, Salvador BA, Brasil.

E-mail: leonardobarros_lob@hotmail.com

(1) http://orcid.org/0000-0002-8406-0515

\section{Rodolfo Augusto Matteo Ambiel}

Doutor em Psicologia. Docente do Programa de Pós-Graduação Stricto Sensu em Psicologia da Universidade São Francisco, Campinas - SP. Brasil.

E-mail: rodolfo.ambiel@usf.edu.br

(1) https:// orcid.org/0000-0002-3921-8547

Endereço para envio de correspondência:

Instituto de Psicologia da Universidade Federal da Bahia. Rua Aristides Novis, 197, Estrada de São Lázaro.

CEP: 40120-730. Salvador - BA. Brasil.

Recebido 12/06/2018

Aceito 22/11/2019

Received 12/06/2018

Approved 22/11/2019

Recibido 12/06/2018

Aceptado 22/11/2019 
Barros, L. O., \& Ambiel, R. A. M. (2020). Instrumentos de avaliação em OPC.

Como citar: Barros, L. O., \& Ambiel, R. A. M. (2020). Instrumentos de Avaliação Psicológica em Orientação de Carreira: Análise da Produção Nacional. Psicologia: Ciência e Profissão, 40, 1-17. https://doi.org/10.1590/1982-3703003203346

How to cite: Barros, L. O., \& Ambiel, R. A. M. (2020). Psychological Assessment Instruments in Vocational Guidance: Analysis of National Production. Psicologia: Ciência e Profissão, 40, 1-17. https://doi.org/10.1590/1982-3703003203346

Cómo citar: Barros, L. O., \& Ambiel, R. A. M. (2020). Instrumentos de Evaluación Psicológica en Orientación de Carrera: Análisis de la Producción Nacional. Psicologia: Ciência e Profissão, 40, 1-17. https://doi.org/10.1590/1982-3703003203346 